\title{
POLYCYSTIC OVARIAN SYNDROME; ASSOCIATION OF BODY MASS INDEX WITH VITAMIN D LEVELS IN WOMEN
}

1. MBBS, M. Phil, MPH Associate Professor, Department of Physiology, Federal Medical and Denta College, Islamabad.

2. MBBS, M. Phil

Assistant Professor, Department of Biochemistry, Federal Medical and Dental College, Islamabad

3. MBBS, M. Phil

Assistant Professor Department of Pharmacology, HBS Medical and Dental College, Islamabad.

Correspondence Address: Dr. Shemaila Saleem

Associate Professor

Department of Physiology

Federal Medical and Dental College

Chak Shehzad Islamabad.

drshemailasaleem@gmail.com

\section{Article received on:}

15/02/2017

Accepted for publication:

20/04/2017

Received after proof reading: 05/06/2017

\section{INTRODUCTION}

Among the ailments of the female endocrine system, Polycystic ovarian syndrome (PCOS) is a common problem faced during the reproductive years characterized by dysfunction of the menstrual cycle, hyperandrogenism, insulin resistance, and polycystic ovaries that can manifest as sexual dysfunction, despair, societal crisis and nuptial catastrophes. ${ }^{1,2}$ It is linked with insulin resistance, obesity, dyslipidemia, diabetes and cardiac diseases. ${ }^{3}$

It has been suggested that diminished vitamin D levels are due to augmented Vitamin D sequestration in fat. ${ }^{4}$ Research work has revealed a negative relationship between obesity, Type II Diabetes Mellitus and levels of vitamin D while certain observational studies have proposed that vitamin $D$ plays a role in insulin secretion and/or action. ${ }^{5}$ Carlin et al. ${ }^{6}$ stated the existence of an inverse association between BMI and 25
Hydroxycholecalciferol (25(OH)D) among very obese African-American individuals. Lagunova et al. ${ }^{7}$ established that $25(\mathrm{OH}) \mathrm{D}$ function as indicator for obesity. ${ }^{8}$

It has been proposed that overweight and obese patients have inverse relationship with 25 Hydroxycholecalciferol and 1,25 Dihydroxycholecalciferol concentration in women suffering from PCOS. ${ }^{9}$ Wortsman et al. acknowledged that obesity is an autonomous threat for causing decreased Vitamin D levels. ${ }^{10}$ Numerous researchers have identified that decreased vitamin $D$ levels in obesity are because of vitamin D sequestration as it is fat soluble into adipose tissues. ${ }^{8,11}$ Mounting evidences have proposed the existence of vitamin $D$ receptor in adipose tissues and its role in obesity by the process of lipogenesis and/or adipogenesis. Certain researchers have proposed the inhibition of fatty acid synthase gene expression, that 
plays a role in lipogenesis in adipose tissues by $1,25(\mathrm{OH})_{2} \mathrm{D} \cdot{ }^{12}$ It has been witnessed that there is a reduced amount of outdoor activity thus reduced exposure to sun light in obese people. ${ }^{13}$ Another research work showed lesser levels of vitamin D in those who have $47 \%$ less outdoor activity than those who do not. ${ }^{14}$

Obesity and vitamin D deficiency are together recognized as global health problems and are believed to be interrelated. No such study has been reported in Pakistan showing association between obesity and vitamin D status in women suffering from Polycystic Ovarian Syndrome. The purpose of our study was to find out the association between $\mathrm{BMI}$ and vitamin $\mathrm{D}$ in females with PCOS because early screening and management of these females with vitamin $D$ can prevent the occurrence of further metabolic disorders and psychosis and ensure them to have healthy reproductive life.

\section{MATERIALS AND METHODS}

The study was carried out after receiving approval from the Institutional Ethical Committee. A written informed consent was acquired from all the participants of our study. It was a descriptive cross-sectional study. This study was conducted at of Railway Hospital (Gynecology and Obstetrics Department), Rawalpindi. The duration of the study was 6 months. There were two groups included in the study; a control group $(n=50)$ and a diseased group $(n=100)$.

We included 50 apparently healthy females of reproductive age group having normal menstrual cycles and none of them exhibited hyperandrogenism. We also included 100 recently diagnosed patients of polycystic ovarian syndrome that were diagnosed on the basis of Rotterdam criteria. The women were labeled as patients of PCOs if two out of the three characteristics were found to be present including ultrasound depiction of polycystic ovarian morphology (existence $\geq 12$ follicles of about 2-9 $\mathrm{mm}$ in diameter per ovary or ovarian volume greater than $10 \mathrm{cc}$ ), biochemical or clinical evident hyperandrogenism like hirsutism, alopecia, acne and / or raised androgen levels) and ovulatory dysfunction (oligomenorrhea/ amnorrhea). The women consuming medications (oral contraceptive pills, hypoglycemic drugs, vitamin $\mathrm{D}$ supplementation) and with other associated problems comprising Cushing syndrome, prolactinemia, thyroid problems and androgen secreting tumor were excluded from the study.

Data was collected using non-probability purposive sampling method. Data was collected from the healthy controls as well as women with PCOS on a self-structured questionnaire including demographic profile like age, occupation, $\mathrm{BMI}$ and other features like age of menarche, genetic history of Polycystic ovarian syndrome, history of any medical ailments and treatment. Hyperandrogenism symptoms among the cases were also recorded. Body weight (kilograms) and height $(\mathrm{m})$ were guaged and calculation of body mass index was done by dividing weight $(\mathrm{kg})$ by the square of the height $\left(\mathrm{m}^{2}\right)$. Participants were classified as normal weight (BMI between 18.5-24.9), overweight (BMI between 25-29.9) and obese (BMI $\geq 30$ ). $3 \mathrm{ml}$ of venous blood was drawn in vaccum clot activator tubes from the participants of cases and control group. The blood samples were centrifuged at 2500-3000 rpm for a duration of $15 \mathrm{~min}$ for the separation of serum. Storage of serum samples was done at $-20^{\circ} \mathrm{C}^{15}$ until it was analyzed at Biochemistry Research Laboratory IIMC. The vitamin D assay was done by Enzyme Linked Immunosorbent Assay by using 250H Vitamin D Total Elisa Kit: Cat\#KAP1917; LOT\#131106 (DIAsource, S.A,Belgium). Vitamin $D$ deficiency was described as "a level of less than $<20 \mathrm{ng} / \mathrm{ml}$ " and vitamin D insufficiency was defined as "a level less than $30 \mathrm{ng} / \mathrm{ml}$ ". ${ }^{16}$.

Data was analyzed by using Statistical Package for the Social Science (SPSS version 21). Data was expressed as Mean \pm standard deviation. Chi-square test was used to see the association of BMI levels and Vitamin D levels in both the groups. The $\mathrm{p}$-value $<0.05$ was considered significant. 


\section{RESULTS}

The results depicted a significant difference in body mass index of both the case and control groups ( $p$-value $<0.05$ ). The body mass index in women suffering from PCOS $(29.021 \pm 4.964)$ was significantly greater ( $p$-value $<0.05$ ) in contrast to the control group $(21.701 \pm 3.541)$ as given in Table-l.

Table-Il depicts the comparison of levels of vitamin between control group and PCOS group on the basis of body mass index classification. No significant ( $p$-value $>0.05$ ) difference in vitamin $\mathrm{D}$ levels were observed when compared between the cases and control groups among normal weight (12.056 \pm 7.742 vs. $11.098 \pm 5.318$, $\mathrm{p}$-value $=0.577)$, over weight $(13.024 \pm 9.798$ vs. $11.032 \pm 6.527, p$-value $=0.526)$ and obese subjects $(6.307 \pm 4.474$ vs. $10.354 \pm 4.993$, p-value $=0.133)$.

Results exhibited that there was no significant (P-value $>0.05$ ) association between vitamin $D$ level and body mass index in the healthy control group as given in detail in Table-III.

Table-IV elaborates that there was no significant ( $p$-value $>0.05$ ) relationship between body mass index and vitamin D level in patients of PCOS.

\begin{tabular}{|c|c|c|c|c|c|}
\hline & & \multirow{2}{*}{$\begin{array}{l}\mathbf{N} \\
50\end{array}$} & & & \multirow{2}{*}{$\begin{array}{c}\text { P value } \\
0.001\end{array}$} \\
\hline \multirow{2}{*}{ Body Mass Index (BMI) } & & & & & \\
\hline & $\begin{array}{c}\text { Population Groups } \\
\text { Control } \\
\text { Cases }\end{array}$ & 100 & \begin{tabular}{|c|}
$\mathbf{M}$ \\
21.701 \\
29.021
\end{tabular} & \begin{tabular}{|c|} 
SD \\
3.541 \\
4.964 \\
\end{tabular} & \\
\hline
\end{tabular}

\begin{tabular}{|l|c|c|c|c|c|}
\hline \multirow{2}{*}{ Body mass Index } & \multicolumn{2}{|c|}{ Controls } & \multicolumn{2}{c|}{ Cases } & p \\
\hline Normal weight & $\mathbf{n}$ & Vit D levels (Mean \pm SD) & $\mathbf{n}$ & Vit D levels Mean \pm SD & 0.577 \\
\hline Over weight & 40 & $12.056 \pm 7.742$ & 20 & $11.098 \pm 5.318$ & 0.526 \\
\hline Obese & 7 & $13.024 \pm 9.798$ & 17 & $11.032 \pm 6.527$ & 0.133 \\
\hline
\end{tabular}

Table-II. BMI and Vitamin D levels between controls and cases (PCOs)

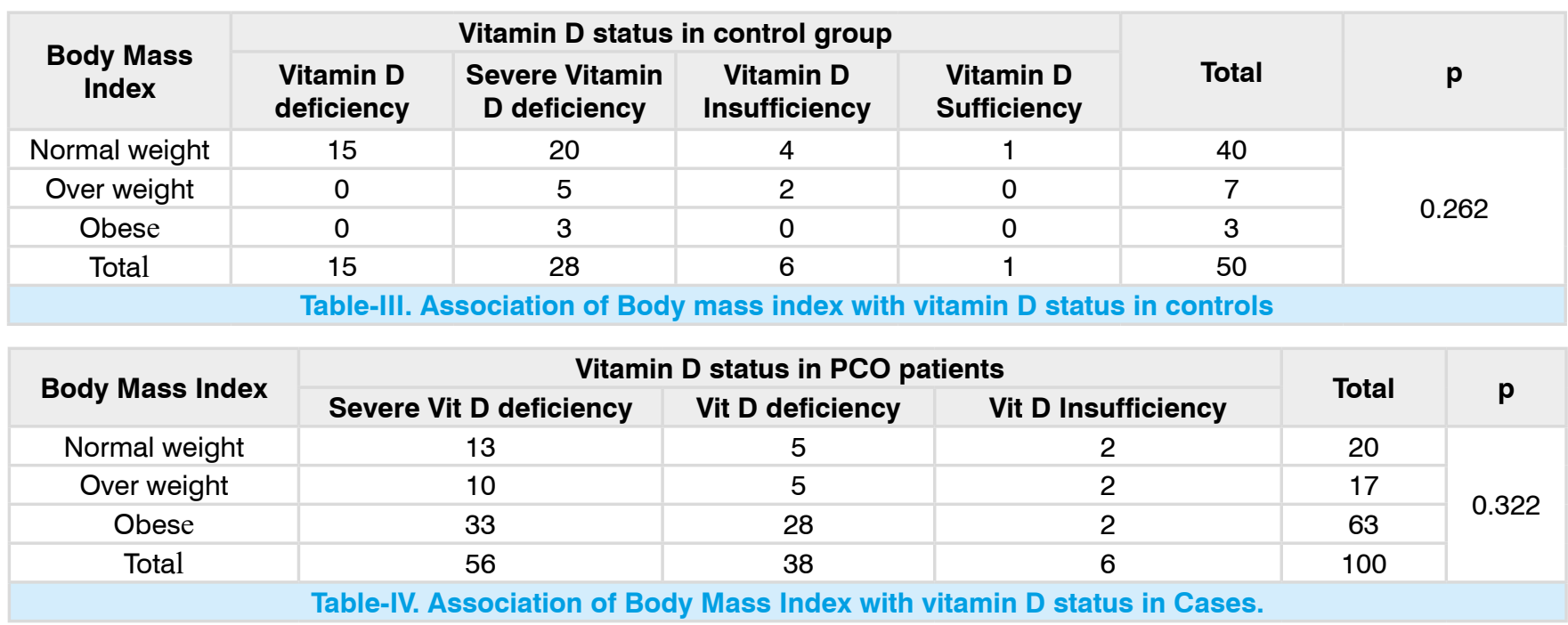

\section{DISCUSSION}

Multiple studies have been carried out to explore the association between vitamin $D$ status and body mass index. The current study showed that $80 \%$ of the women in control group had normal weight and $6 \%$ of them were found to be obese. Conversely in women suffering from PCOS, $63 \%$ women were found to be obese and only $20 \%$ women exhibited normal weight. Our study discovered that the BMl in women with 
PCOS (27.094+4.369) was substantially ( $p$-value $<0.05)$ more in contrast to the healthy controls $(20.739 \pm 3.452)$. This findings are similar to the results of the some other studies. ${ }^{17,18}$ Mirza SS et al also established that serum adiponectin levels are autonomously related with PCOS and are only partially elucidated by Insulin Resistance. Adiponectin level which are inversely related with obesity in PCOS patients may function as a prospective independent biomarker for diagnosis of PCOS in young and lean women with less symptoms, or women having a positive family history of PCOS. ${ }^{19}$ No significant ( $p$-value $>0.05$ ) difference was observed between vitamin $D$ levels across a range of Body mass Indices among control and patients with PCOS though, in the control group we had 03 obese $(\mathrm{BMI} \geq 30)$ and 20 normal weight women who had severe vitamin D deficiency while 33 obese and 13 normal weight PCOS patients suffered severe vitamin $D$ deficiency displaying that obese and normal weight women in both the cases and controls had same vitamin D status. The descriptive cross sectional research work carried out by Faraj et al in 2014 also established that there exists no significant relationship between body mass index and vitamin D levels. ${ }^{20}$ Comparable outcome was also acquired by in another study in which 38 Korean women (18-40 years) were recruited with PCOS and 109 age and BMI matched non PCOS women were included. ${ }^{16}$ Another research work was conducted in Iran by Firouzabadi et al. on 100 infertile PCOS women also observed no significant association between BMl and serum vitamin $D$ level before and after the management with vitamin $\mathrm{D}$ and calcium supplements. ${ }^{21}$

Numerous studies have exhibited an inverse relationship between vitamin $\mathrm{D}$ and $\mathrm{BMI}$ in women with PCOS in the reproductive age group. ${ }^{22,23,15,24}$ Where et al. likewise established a robust association between vitamin $\mathrm{D}$ concentration in women with PCOS and body mass index and stated that PCOS women presenting with metabolic syndrome had lesser vitamin D level than PCOS women without these features (17.3 vs $25.8 \mathrm{ng} / \mathrm{ml}$ respectively). ${ }^{25,19}$ However we did not find any significant association between vitamin
D deficiency and BMI in both groups (controls and cases).

The limitations in our study are the small sample size and lack of adjustments for confounding factors. To the best of our knowledge we are the first to investigate the association between body mass index and vitamin D status in PCOS in women in Pakistan. To prove our results novel therapeutic methodologies and hefty intervention trials are a prerequisite.

Copyright(C) 20 Apr, 2017.

\section{REFERENCES}

1. Mukherjee S, Shaikh N, Dadachanji R, Shah N, Patil A. Understanding insulin resistance pathophysiology in PCOS: a genetic approach. Molecular Cytogenetics. 2014;7(Suppl 1):P92.

2. Bazarganipour F, Ziaei S, Montazeri A, Foroozanfard F, Faghihzadeh $S$. Iranian version of modified polycystic ovary syndrome health-related quality of Life questionnaire: Discriminant and convergent validity. Iranian journal of reproductive medicine. 2013;11(9):753-60.

3. Nandalike K, Agarwal C, Strauss T, Coupey SM, Isasi $\mathrm{CR}$, Sin S, et al. Sleep and cardiometabolic function in obese adolescent girls with polycystic ovary syndrome. Sleep medicine. 2012;13(10):1307-12.

4. Earthman C, Beckman L, Masodkar K, Sibley S. The link between obesity and low circulating 25-hydroxyvitamin D concentrations: considerations and implications. International journal of obesity. $2011 ; 36(3): 387-96$.

5. Cândido FG, Bressan J. Vitamin D: link between osteoporosis, obesity, and diabetes? International journal of molecular sciences. 2014;15(4):6569-91.

6. Carlin AM, Rao DS, Meslemani AM, Genaw JA, Parikh NJ, Levy S, et al. Prevalence of vitamin D depletion among morbidly obese patients seeking gastric bypass surgery. Surgery for Obesity and Related Diseases. 2006;2(2):98-103.

7. Lagunova Z, Porojnicu AC, Vieth R, Lindberg FA, Hexeberg S, Moan J. Serum 25-hydroxyvitamin D is a predictor of serum 1, 25-dihydroxyvitamin D in overweight and obese patients. The Journal of nutrition. 2011;141(1):112-7.

8. Earthman C, Beckman L, Masodkar K, Sibley S. The link between obesity and low circulating 25-hydroxyvitamin D concentrations: considerations 
and implications. International journal of obesity. 2012;36(3):387-96.

9. Tehrani HG, Mostajeran F, Shahsavari S. The effect of calcium and vitamin $D$ supplementation on menstrual cycle, body mass index and hyperandrogenism state of women with poly cystic ovarian syndrome. J Res Med Sci. 2014;19:875-80.

10. Luk J, Torrealday S, Perry GN, Pal L. Relevance of vitamin $D$ in reproduction. Human reproduction. 2012;27(10):3015-27.

11. Blum M, Dolnikowski G, Seyoum E, Harris SS, Booth SL, Peterson J, et al. Vitamin D3 in fat tissue. Endocrine. 2008;33(1):90-4.

12. Kong $\mathrm{J}$, Li YC. Molecular mechanism of 1, 25-dihydroxyvitamin D3 inhibition of adipogenesis in 3T3-L1 cells. American Journal of PhysiologyEndocrinology and Metabolism. 2006;290(5):E916-E24.

13. Kull $M$, Kallikorm R, Lember $M$. Body mass index determines sunbathing habits: implications on vitamin D levels. Internal medicine journal. 2009;39(4):256-8.

14. Florez $H$, Martinez $R$, Chacra $W$, Strickman-Stein $\mathrm{N}$, Levis $\mathrm{S}$. Outdoor exercise reduces the risk of hypovitaminosis $D$ in the obese. The Journal of steroid biochemistry and molecular biology. 2007;103(3):67981.

15. Hahn S, Haselhorst U, Tan S, Quadbeck B, Schmidt $M$, Roesler S, et al. Low serum 25-hydroxyvitamin D concentrations are associated with insulin resistance and obesity in women with polycystic ovary syndrome. Experimental and clinical endocrinology \& diabetes: official journal, German Society of Endocrinology [and] German Diabetes Association. 2006;114(10):577-83.

16. Kim JJ, Choi YM, Chae SJ, Hwang KR, Yoon SH, $\mathrm{Kim} M J$, et al. Vitamin D deficiency in women with polycystic ovary syndrome. Clinical and experimental reproductive medicine. 2014;41(2):80-5.

17. Joshi B, Mukherjee S, Patil A, Purandare A, Chauhan $S$, Vaidya R. A cross-sectional study of polycystic ovarian syndrome among adolescent and young girls in Mumbai, India. Indian journal of endocrinology and metabolism. 2014;18(3):317.

18. Wang $X$, Yang $Y$, Huang $Y$, Wang Q. Association study of polymorphism of FXIIIVal34Leu gene and polycystic ovary syndrome. International journal of clinical and experimental medicine. 2014;7(11):4466.

19. Mirza SS, Shafique K, Shaikh AR, Khan NA, Qureshi MA. Association between circulating adiponectin levels and polycystic ovarian syndrome. Journal of ovarian research. 2014;7(1):1.

20. Faraji R, Sharami SH, Zahiri Z, Asgharni M, Kazemnejad E, Sadeghi S. Evaluation of Relation between Anthropometric Indices and Vitamin D Concentrations in Women with Polycystic Ovarian Syndrome. Journal of family \& reproductive health. 2014;8(3):123.

21. dehghani Firouzabadi R, Aflatoonian A, Modarresi S, Sekhavat L, MohammadTaheri S. Therapeutic effects of calcium \& vitamin D supplementation in women with PCOS. Complementary therapies in clinical practice. 2012;18(2):85-8.

22. Li HWR, Brereton RE, Anderson RA, Wallace AM, Ho $C K$. Vitamin $D$ deficiency is common and associated with metabolic risk factors in patients with polycystic ovary syndrome. Metabolism. 2011;60(10):1475-81.

23. Mazloomi S, Sharifi F, Hajihosseini R, Kalantari $S$, Mazloomzadeh S. Association between hypoadiponectinemia and low serum concentrations of calcium and vitamin $D$ in women with polycystic ovary syndrome. ISRN endocrinology. 2012;2012.

24. Christensen SB, Black MH, Smith N, Martinez MM, Jacobsen SJ, Porter AH, et al. Prevalence of polycystic ovary syndrome in adolescents. Fertility and sterility. 2013;100(2):470-7.

25. Wehr E, Pilz S, Schweighofer N, Giuliani A, Kopera $\mathrm{D}$, Pieber T, et al. Association of hypovitaminosis D with metabolic disturbances in polycystic ovary syndrome. European Journal of Endocrinology. 2009;161(4):575-82.

\section{AUTHORSHIP AND CONTRIBUTION DECLARATION}

\begin{tabular}{|c|c|c|c|}
\hline Sr. \# & Author-s Full Name & Contribution to the paper & Author $=$ s Signature \\
\hline 1 & $\begin{array}{l}\text { Dr. Shemaila Saleem } \\
\text { Dr. Fauzia Hanif } \\
\text { Dr. Amanat Ali }\end{array}$ & $\begin{array}{l}\text { Idea and designing, Analysis of } \\
\text { data, Composition of article } \\
\text { Idea and designing, Analysis of } \\
\text { data, Composition of article } \\
\text { Idea and designing, Composition } \\
\text { of article }\end{array}$ & $s$ \\
\hline
\end{tabular}

